\title{
Ontogenetic changes in vertical migratory rhythms of benthopelagic shrimps Pasiphaea multidentata and $P$. sivado
}

\author{
Jacopo Aguzzi*, Joan Baptista Company, Pere Abelló, José Antonio García
}

Institut de Ciències del Mar (CSIC), Passeig Marítim de la Barceloneta 37-49, 08003 Barcelona, Spain

\begin{abstract}
Vertical migratory rhythms of the western Mediterranean congeneric benthopelagic glass shrimps Pasiphaea sivado and P. multidentata were studied at depths of 400 to $430 \mathrm{~m}$ in relation to light intensity cycles (i.e. light regimes) in 2 different seasons: close to the autumn equinox (October) and to the summer solstice (June). Catches were considered a proxy of animal density close to the bottom and sampling was performed with consecutive epibenthic trawl hauls. These were continuously repeated over $4 \mathrm{~d}$ in order to determine the frequency and timing of species presence on the bottom. The density of animals present on the seabed at the time of the haul was estimated. In both $P$. sivado and $P$. multidentata marked diel differences in density were found which were correlated to variability in diel light intensity. While $P$. sivado was mostly captured at daytime in both seasons, regardless of size, $P$. multidentata only showed this pattern in the case of juveniles, i.e. individuals with carapace length $<30 \mathrm{~mm}$. Adult $P$. multidentata were mainly present on the bottom during the night, thus showing an apparent phase inversion in their movement patterns. This modification of diel behaviour can be interpreted as the result of differential habitat use with size/age. The comparison of present results with previous field studies illustrates that while $P$. sivado and juvenile $P$. multidentata perform actual vertical migrations, adults of the latter species undertake epibenthic movements along the bottom.
\end{abstract}

KEY WORDS: Pasiphaea sivado · Pasiphaea multidentata $\cdot$ Ontogeny $\cdot$ Vertical migratory rhythms · Continental slope $\cdot$ Light intensity $\cdot$ Photoperiod length $\cdot$ Behavioural activity

Resale or republication not permitted without written consent of the publisher

\section{INTRODUCTION}

The occurrence of life stages with different behavioural rhythms helps to reduce intraspecific competition via partitioning of time of access to and exploitation of similar resources (e.g. Kronfeld-Schor \& Dayan 2003). In crustaceans, modifications of behavioural attitude and rhythm have been shown to occur in adults in response to an increment of size (e.g. Naylor \& Kennedy 2003). Such data often refer to shallowwater areas, but in deep-water habitats the difficulty in sampling and the multitude of unpredictable physical factors affecting individual behaviour complicate the characterization of rhythms during ontogeny (Saigusa \& Akiyama 1995). Most species, both in the terrestrial and in the marine milieu, synchronize their behaviour with the day-night cycle (e.g. Naylor 2005), since light influences how organisms perceive their environ- ment. Illumination affects the typology and level of intraspecific and interspecific competition within a particular habitat (McIntosh \& Townsend 1994).

Vertical migrations in response to light cycles are an extensively documented phenomenon occurring in all oceans (e.g. Oishi \& Saigusa 1997, Sardà et al. 2003). Such movement is important for the transfer of energy from the epipelagic to the benthic realm (e.g. Lagardére 1977, Cartes 1993a, Bergstand et al. 2003). The benthopelagic glass shrimps Pasiphaea sivado (Risso 1816) and P. multidentata Esmark 1866 play a key role in this process due to their high biomass (e.g. Company et al. 2001, Bergstand et al. 2003). In the western Mediterranean, $P$. sivado shows a peak in its distribution on the upper slope (200 to $600 \mathrm{~m}$ ), whereas the main depth distribution of $P$. multidentata is found on the middle slope (400 to 800 m) (e.g. Abelló et al. 2002). 
Both species show vertical migrations coupled to the day-night cycle, despite the difference in their bathymetric distributions (e.g. Franqueville 1971, Cartes 1993a, Cartes et al. 1993, Macquart-Moulin \& Patriti 1996). Few reports, however, exist on the precise timing and duration of the species presence on the bottom over the $24 \mathrm{~h}$ day-night cycle, since most of the available data on differential depth distribution of continental slope shrimps have been obtained either from commercial trawlers, whose activity is legally controlled during the day, or from demersal trawl surveys, which also take place during the day (Bertrand et al. 2002). In the present study, the temporal patterns of occurrence of pasiphaeid shrimps on the continental slope and their modifications with ontogeny were investigated using demersal trawl hauls taken over the $24 \mathrm{~h}$ day-night cycle over $4 \mathrm{~d}$ in 2 seasons: close to the autumn equinox (October) and to the summer solstice (June). Catch patterns were used as a proxy of duration and timing of the species' presence on the seabed in relation to measured light intensity cycles and photoperiod length. Density changes of both species were analysed, taking into account the size at maturity of animals in order to study the modulation of their vertical migratory rhythms with ontogeny.

\section{MATERIALS AND METHODS}

Sampling. The study area (Fig. 1) is located on the western Mediterranean continental slope and sam-

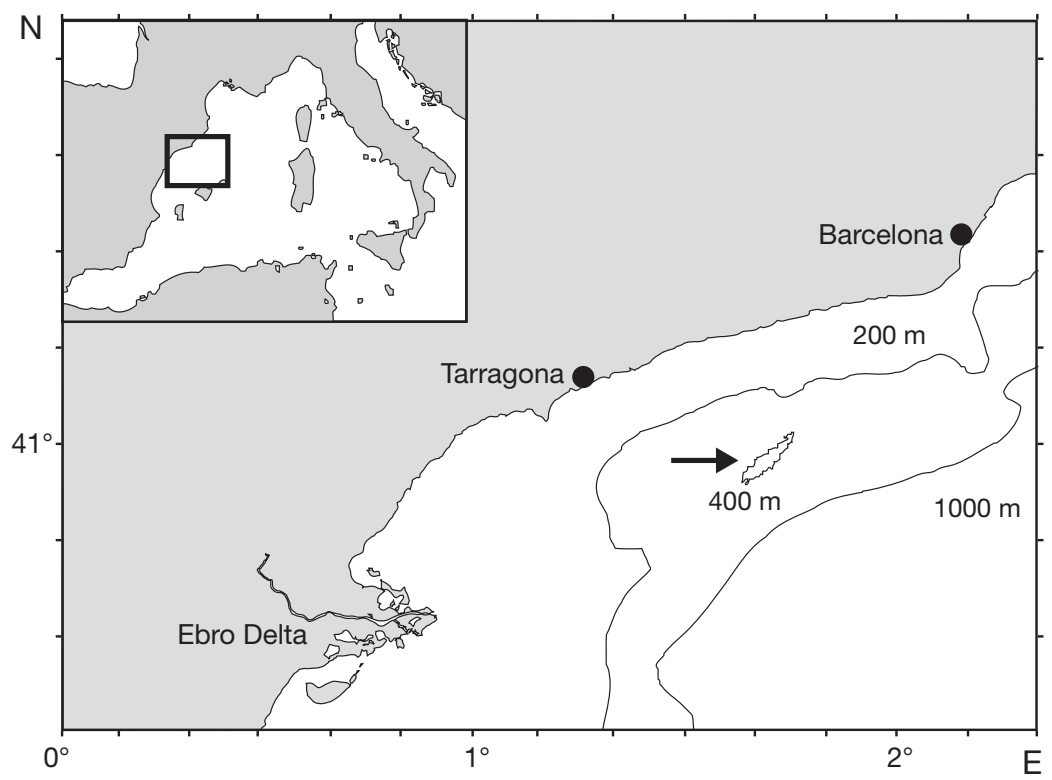

Fig. 1. Sampling areas in October (28 September to 8 October 1999) and June (22 June to 3 July 2000) off the Catalan coast, western Mediterranean. Arrow: transect hauls at $400-430 \mathrm{~m}$. Continuous lines depict coast profile, 200 and $1000 \mathrm{~m}$ isobaths pling was performed at 400 to $430 \mathrm{~m}$ depth off Tarragona, Spain $\left(41^{\circ} 01^{\prime} \mathrm{N}, 1^{\circ} 37^{\prime} \mathrm{E} ; 40^{\circ} 55^{\prime} \mathrm{N}, 1^{\circ} 31^{\prime} \mathrm{E}\right)$. Two research cruises were carried out during 2 different seasons to study the possible modulation of behavioural activity by variations in photoperiod length. Sampling occurred at the autumn equinox (28 September to 8 October 1999), with ca. $12 \mathrm{~h}$ day and $12 \mathrm{~h}$ night, and during the summer solstice (22 June to 3 July 2000), when daylight hours (15 h) far exceeded night-time hours (9 h).

All field surveys were performed onboard the RV 'García del Cid' (38 m length; 1200 HP) equipped with an epibenthic otter trawl 'Maireta' gear of $27.5 \mathrm{~mm}$ cod-end mesh size (OTMS), with a vertical opening spanning 1.4 to $1.6 \mathrm{~m}$ from the bottom. This gear is suited for bottom trawling, its 'mouth' being collapsed when lowered onto the seabed or when recollected on board, when the opening 'doors' are not being used. This prevents the accidental capture of mesopelagic species from the water column.

A total of 34 and 31 hauls were performed in October and June, respectively. Replicate trawl hauls of $1 \mathrm{~h}$ duration at a speed of 2.5 knots were sequentially repeated along the bottom (400 to $430 \mathrm{~m}$ depth) over $24 \mathrm{~h}$ during 4 consecutive days at intervals of 3 to $4 \mathrm{~h}$. Trawling was performed along parallel and anti-sense transects of $4.7 \pm 1.4 \mathrm{~km}$ located in close proximity to one another in the same fishing ground and depth. Trawls were not equally spaced in time, given the complexity of technical operations related to net maintenance and light intensity sampling (see below). A GPS system recorded the ship velocity and the initial and final position for all hauls, while the echo-sounder provided depth measures. Probes of trawl sensor technology (Scanmar) were connected to the net mouth to record the proper functioning of the gear. Data were telemetrically saved every minute on an on board computer. Initial and final trawl times were recorded by noting the time of the gear landing and rising from the seabed.

Light intensity was sampled between consecutive hauls and not during trawling, since a steady positioning of the boat was required. The photometer employed (LI193SA Spherical Quantum Sensor) was mounted on a CTD and it measured the light intensity as Photon Fluence Rate (PFR, $\mu E_{i} m^{-2} s^{-1}$ ) in a wavelength range between 400 and $700 \mathrm{~nm}$. The illumination on the slope was below the sensitivity range of the photometer and consequently light could be directly sampled only down to $300 \mathrm{~m}$ depth. The illumination at 400 to $430 \mathrm{~m}$ 
depth was calculated by multiplying values obtained at $300 \mathrm{~m}$ by an attenuation coefficient $(K)$ that quantifies the effect of water column absorption and scattering on incoming radiation; see Tobar \& Sardà (1992) for details of the procedure employed.

Catchability rhythms. For each haul, all individuals of both species were sorted, counted, and their carapace length (CL) sized using a digital calliper with $\pm 0.1 \mathrm{~mm}$ precision. Individuals were sorted into 2 size categories, juveniles and adults, taking into account size at first maturity (Company et al. 2001 and authors' unpubl. data): Pasiphaea sivado $=15 \mathrm{~mm} \mathrm{CL;} \mathrm{P.} \mathrm{multi-}$ dentata $=30 \mathrm{~mm}$ CL.

Catches were considered to be directly proportional to numbers of animals present on the bottom at the time of the haul. In this way, temporal variations in captures were used as a proxy of vertical migratory rhythms of animals over the $24 \mathrm{~h}$ cycle (e.g. Aguzzi et al. 2006). Density per haul was obtained by dividing the number of sampled individuals for each size category by the swept area $\left(\mathrm{km}^{2}\right)$, estimated from Scanmar and GPS data (Sparre et al. 1989). Density was plotted as a function of the start time of each haul (i.e. timing of net landing onto seabed) and the time of sunset and sunrise at the latitude of the study area (GMT: 17:39 and 05:44 h on 28 September; 19:27 and 04:19 h on 22 June).

In chronobiology, waveforms are computed in order to assess the phase (i.e. timing of peaks) of biological rhythms. The temporal relationship in the phase of different rhythms can be assessed when data are taken at corresponding time intervals (e.g. Dunlap et al. 2004). The phase of vertical migratory rhythms (i.e. timing of abundance peaks at the seabed) in relation

Table 1. Number of hauls and PFR readings used to estimate average light intensity and density of Pasiphaea sivado and $P$. multidentata within each $2 \mathrm{~h}$ interval at autumn equinox (October) and summer solstice (June). np: nocturnal period; - : no samples collected

\begin{tabular}{|c|c|c|c|c|}
\hline \multirow{2}{*}{$\begin{array}{l}\text { Time } \\
\text { interval } \\
\text { (h) }\end{array}$} & \multicolumn{2}{|c|}{$\begin{array}{l}\text { No. of } \\
\text { hauls }\end{array}$} & \multicolumn{2}{|c|}{$\begin{array}{c}\text { No. of } \\
\text { PFR readings }\end{array}$} \\
\hline & October & June & October & June \\
\hline $0-2$ & 1 & 2 & $\mathrm{np}$ & np \\
\hline $2-4$ & 2 & 2 & $\mathrm{np}$ & $\mathrm{np}$ \\
\hline $4-6$ & 2 & 4 & np & 2 \\
\hline $6-8$ & 3 & 3 & 4 & 3 \\
\hline $8-10$ & 5 & 3 & 3 & 2 \\
\hline $10-12$ & 3 & 1 & 3 & 3 \\
\hline $12-14$ & 3 & 3 & 3 & 1 \\
\hline $14-16$ & - & 1 & 4 & - \\
\hline $16-18$ & 4 & 4 & 1 & 3 \\
\hline $18-20$ & 3 & 4 & 1 & 4 \\
\hline $20-22$ & 4 & 4 & np & np \\
\hline $22-0$ & 4 & - & np & np \\
\hline
\end{tabular}

to the light cycle was statistically assessed by performing waveform analysis on density and PFR time series. All values obtained within $2 \mathrm{~h}$ intervals on each of the $4 \mathrm{~d}$ were averaged $( \pm \mathrm{SD}$; Table 1$)$. For those intervals where a single or no haul occurred (due to technical reasons), a density average $( \pm \mathrm{SD})$ was estimated from all values falling into adjacent $2 \mathrm{~h}$ intervals, e.g. the missing value in the 14-16 h interval in October was obtained by averaging all density measures occurring within the 12-14 $\mathrm{h}$ and 16-18 $\mathrm{h}$ intervals $(N=7)$. For each plot of mean density, the phase was identified by computing its onset and offset. A daily mean was calculated by averaging all mean densities and this was represented as a horizontal line into the plots (see Fig. 3). Values above that threshold constituted the significant peak and the first value above and below it were taken as the onset and the offset, respectively, of the significant peak (Aguzzi et al. 2003).

\section{RESULTS}

Densities of Pasiphaea sivado (Fig. 2A) were on average higher in the summer solstice than in the autumn equinox. For juvenile P. multidentata (Fig. 2B) the inverse pattern was observed, with highest densities found in the autumn equinox. Densities of adult P. multidentata were of similar magnitude in both seasons and consistently lower than those reported for juveniles (Fig. 2B). Light intensity fluctuation was larger in the autumn equinox than in the summer solstice, i.e. maxima of $2.66 \times 10^{-7} \mu \mathrm{E}_{\mathrm{i}} \mathrm{m}^{-2} \mathrm{~s}^{-1}$ in October, $6.8 \times$ $10^{-8} \mu \mathrm{E}_{\mathrm{i}} \mathrm{m}^{-2} \mathrm{~s}^{-1}$ in June.

The temporal patterns of density of Pasiphaea sivado presented clear diurnal increases in both seasons (Fig. 2A). Maxima were always coincident with highest light intensity. Analysis of catch patterns based on size groups (CL $<15 \mathrm{~mm}$ and CL $>15 \mathrm{~mm}$ ) did not present differences since plot profiles and timing of peaks fully coincided (data not shown).

Densities of juvenile Pasiphaea multidentata (CL < $30 \mathrm{~mm}$ ) in the autumn equinox displayed highest values at high light intensities (Fig. 2B); in the summer solstice a more variable pattern was present, but maxima in catches still occurred during daytime. Densities of adult $P$. multidentata ( $\mathrm{CL}>30 \mathrm{~mm}$, Fig. 2C) increased at night-time both in the autumn equinox and in the summer solstice. Density minima clearly coincided with increases in light intensity; this was especially evident in the summer solstice.

The waveform profile of PFR data (Fig. 3) showed higher values of intensity over a similar period of time in October than in June in agreement with raw data patterns (Fig. 2). The mean density plot for Pasiphaea 

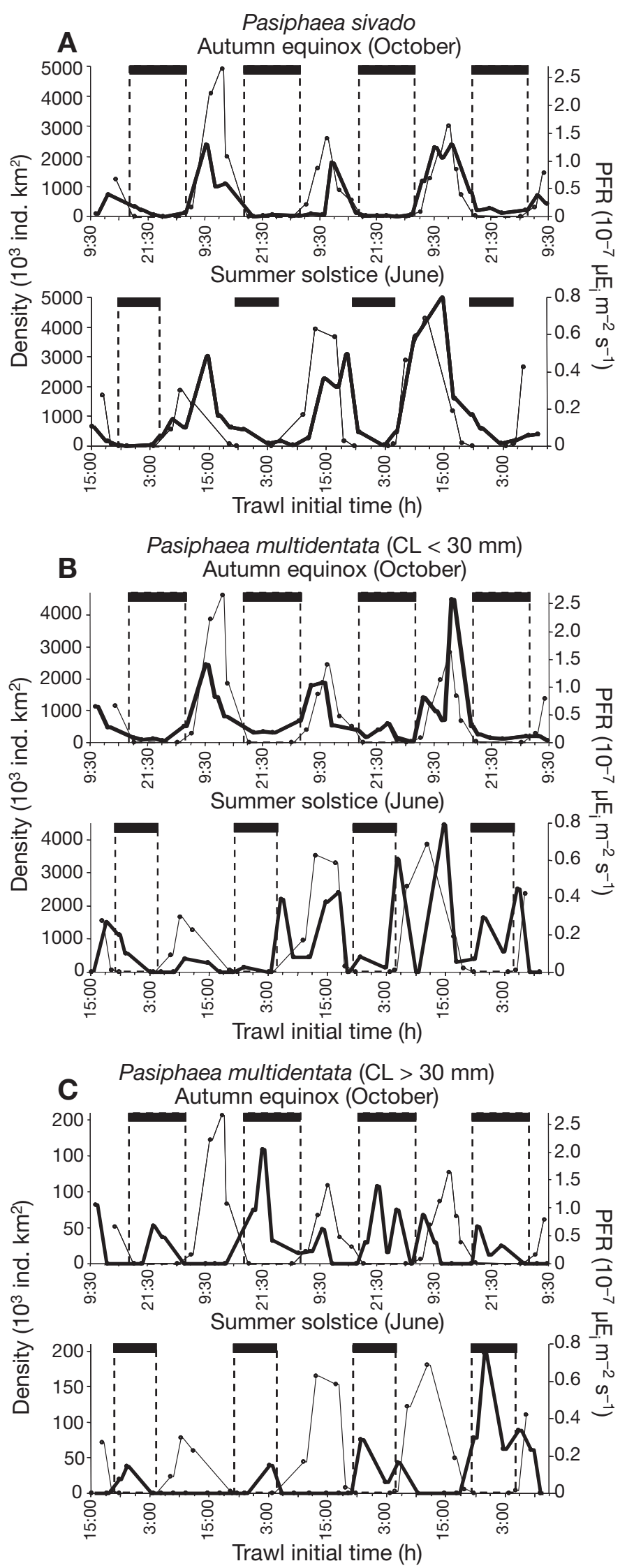

sivado closely coincided with the light cycle in both sampled seasons (Fig. 3A). The onset of the timing of occurrence on the bottom was in the $6-8 \mathrm{~h}$ interval in October and in the 8-10 $\mathrm{h}$ interval in June; the offset was found in the 14-16 $\mathrm{h}$ interval in October and in the $18-20 \mathrm{~h}$ in June.

The waveform analysis for juvenile Pasiphaea multidentata (CL $<30 \mathrm{~mm}$ ) showed more variability in the summer solstice than in the autumn equinox (Fig. 3B), when it more closely followed the light cycle. In autumn, densities increased above the daily mean from $6-8 \mathrm{~h}$ to $14-16 \mathrm{~h}$, a temporal window similar to that already reported for P. sivado (Fig. 3A). In June, a diurnal phase could still be identified since maxima always took place during the daytime (i.e. 4-6 h, 12-14 $\mathrm{h}$ and $16-18 \mathrm{~h}$ ). The first significant increase of abundance in June took place at $4-6 \mathrm{~h}$, anticipating by $2 \mathrm{~h}$ that recorded in October (6-8 h). In June the offset of the occurrence on the bottom was at 16-18 $\mathrm{h}$ with a $2 \mathrm{~h}$ delay when compared to October (14-16 h).

In both sampled seasons, adult Pasiphaea multidentata (CL > $30 \mathrm{~mm}$ ) (Fig. 3C) showed a markedly different behaviour than that recorded for juveniles (Fig. 3B) and for P. sivado (Fig. 3A). Densities were much higher during the night than during the day, when they practically disappeared from catches during intervals of highest light intensity, from 8-10 to $16-18 \mathrm{~h}$.

\section{DISCUSSION}

Marked patterns of occurrence and density variations of Pasiphaea sivado and P. multidentata on the continental slope bottom in relation to light intensity cycles were recorded in this study. In both the autumn equinox (October) and summer solstice (June), densities of $P$. sivado just off the seabed were much higher at daytime than at night-time, while $P$. multidentata showed this pattern only for juveniles ( $\mathrm{CL}<30 \mathrm{~mm}$ ). Conversely, adult $P$. multidentata (CL $>30 \mathrm{~mm}$ ) were captured in significant numbers during the night. While the pattern found for P. multidentata could be interpreted as a modification of their migratory rhythm upon ontogeny, closer examination and previous references indicate that adults of this species change their habitat from the water column down to the seabed. Thus, these findings are in agreement with Fran-

Fig. 2. Density (no. $\mathrm{km}^{-2}$ ) of Pasiphaea sivado (A) and P. multidentata juveniles (B) and adults (C), in relation to light intensity cycles (i.e. $P F R, \mu E_{i} m^{-2} s^{-1}$ ), as recorded during $4 \mathrm{~d}$ of fishing activity at $400-430 \mathrm{~m}$ at autumn equinox (28 September to 8 October 1999) and summer solstice (22 June to 3 July 2000). Horizontal black bars on the top represent night duration. (一): catch patterns; (-): PFR patterns 

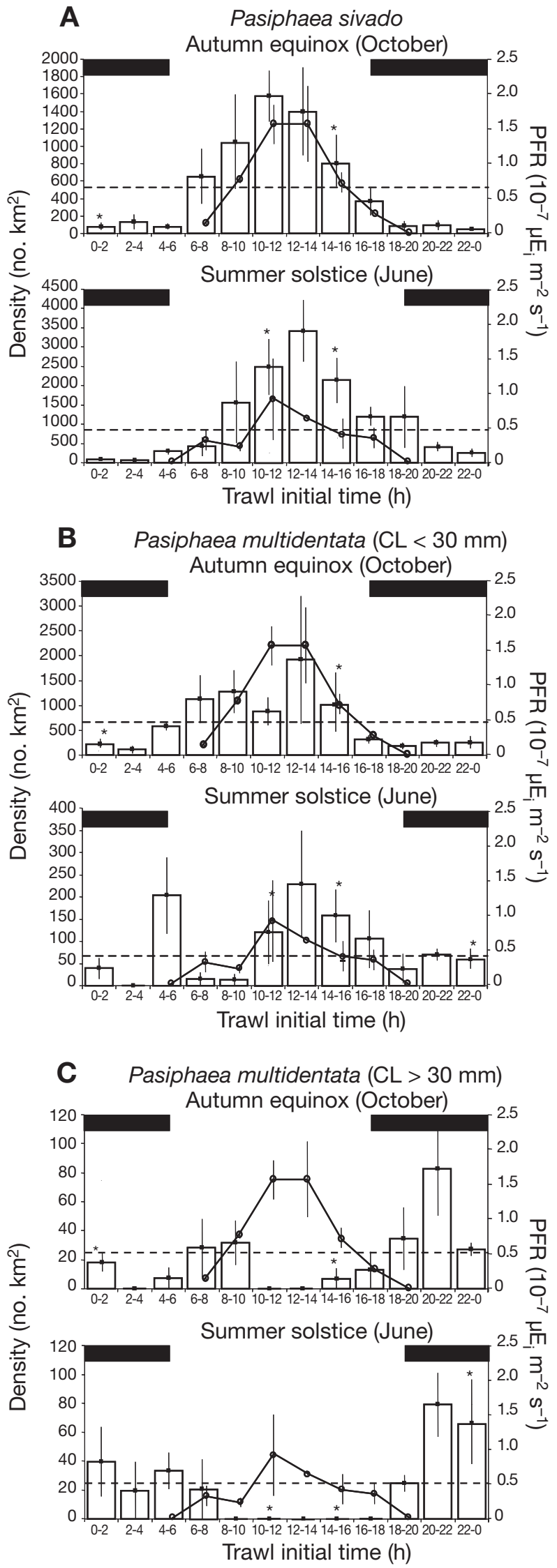

queville (1971) who, regardless of size, reported diel migrations in the water column from $400-500 \mathrm{~m}$ in the day up to ca. $100 \mathrm{~m}$ in the night for P. sivado, and from $800-900 \mathrm{~m}$ in the day up to $100-200 \mathrm{~m}$ in the night for P. multidentata.

In this study, light was shown to exert a modulation on the migratory behaviour of pasiphaeid shrimps at both diel and seasonal time scales. Thus, Pasiphaea sivado were present in significant numbers on or close to the seabed only above light intensity (PFR) values around $7.0 \times 10^{-8} \mu \mathrm{E}_{\mathrm{i}} \mathrm{m}^{-2} \mathrm{~s}^{-1}$ in autumn and $5.0 \times$ $10^{-8} \mu \mathrm{E}_{\mathrm{i}} \mathrm{m}^{-2} \mathrm{~s}^{-1}$ in the summer solstice (Fig. 3A). Juvenile Pasiphaea multidentata showed a significant increase in their sampled density at light intensities close to $5.0 \times 10^{-8} \mu \mathrm{E}_{\mathrm{i}} \mathrm{m}^{-2} \mathrm{~s}^{-1}$ in both October and June (Fig. 3B). By contrast, adult $P$. multidentata were present in both seasons only when light dropped below $5.0 \times 10^{-8} \mu \mathrm{E}_{\mathrm{i}} \mathrm{m}^{-2} \mathrm{~s}^{-1}$ and $4.5 \times 10^{-8} \mu \mathrm{E}_{\mathrm{i}} \mathrm{m}^{-2} \mathrm{~s}^{-1}$, i.e. in practical darkness (Fig. 3C).

The present study focused on a constant depth range $(400-430 \mathrm{~m})$ that allowed characterization of catch patterns as a proxy of species presence and density at the time of the haul. Adult Pasiphaea multidentata were accordingly present on the upper slope during the night, disappearing at daytime. Conversely, densities of adult individuals in the middle slope (700 to $900 \mathrm{~m}$ ) increased during the day (Company et al. 2001, Sardà et al. 2003). Also, Cartes et al. (1993) reported differences in size composition of $P$. multidentata in commercial catches in a day-night experiment, with juveniles increasing their presence at daytime. Present data can be interpreted by assuming that adult $P$. multidentata move along the seabed on a diel basis between the middle and upper slope (see also Cartes et al. 1993). This scenario seems to be confirmed by the feeding behaviour of pasiphaeids in the area (Cartes 1993a,b). Both species show very little dietary overlap, with adult $P$. multidentata feeding on benthic species while juveniles and $P$. sivado feed on pelagic prey (Cartes 1993b).

In studies on behavioural rhythms, the active phase is identified using waveform analysis as a significant increase in the rate of locomotor, flying or swimming

Fig. 3. Mean estimates in light intensity $\left(P F R, \mu E_{i} m^{-2} s^{-1}\right.$; dots) and abundance (no. $\mathrm{km}^{-2}$; histograms) of Pasiphaea sivado (A) and Pasiphaea multidentata juveniles (B) and adults (C), at 400-430 m during the autumn equinox (28 September to 8 October 1999) and summer solstice (22 June to 3 July 2000). Mean values per $2 \mathrm{~h}$ interval are presented \pm $\mathrm{SD}$. Single or missing mean density estimate (*) and missing light intensity (o) values replaced by averages computed from values falling into adjacent $2 \mathrm{~h}$ intervals. (---) Daily mean in density data as computed to define the phase, i.e. significant increases in catches 
activity over a basal threshold (e.g. Dunlap et al. 2004). The activity phase in benthopelagic shrimps can be assessed in the field as the time window in which feeding occurs (e.g. Fanelli \& Cartes 2004). Pasiphaea sivado and juvenile $P$. multidentata ( $\mathrm{CL}<30 \mathrm{~mm}$ ) can be considered as nocturnal feeders. Animals reach the bottom during daytime in accordance with their vertical migration pattern (Franqueville 1971). On the seabed, neither juvenile $P$. multidentata nor $P$. sivado feed (Lagardère 1977, Cartes 1993b); they actively move upward at night-time, hence disappearing from seabed catches, in order to feed on organisms in the upper layers of the water column. From present data, adult $P$. multidentata apparently behave in an opposite manner: adults are captured only at night, but feeding takes mainly place during the night (Cartes 1993b). In this sense, the phase of their activity rhythm remains unaltered but the modification in their migratory behaviour during ontogeny would take place in reference to habitat utilization: displacement along the seabed rather than into the water column (see also Cartes et al. 1993).

The understanding of changes in behaviour upon ontogeny in response to selective pressures is a central subject of behavioural ecology (Joshi 2005). In the present case, individuals perform daily movements from the bottom into the water column and along the bottom, the timing of which may vary upon growth, in order to reach depth locations where the illumination maximizes their strategies of predator avoidance, feeding or resting (Kronfeld-Schor \& Dayan 2003). A number of studies showed that larger adults tend to be found in deeper areas than smaller juveniles due to predation pressure, especially in the case of visual predators (e.g. De Robertis 2002). The change in habitat utilization of Pasiphaea multidentata is elicited upon ontogeny by a differential visibility of adults to nektonic predators of the mesopelagic habitat (Frank 2003). Adult $P$. sivado and juvenile $P$. multidentata are of similar size, being equally transparent at night-time (Johnsen 2005). During the day, both species similarly avoid pelagic predators by staying close to the seabed. Conversely, in adult $P$. multidentata opacity probably increases due to increased pigmentation. Accordingly, adults of this species may equally avoid the water column at any time of the day. They reach the upper slope (at the present sampled depths) to feed at night when the illumination is low and avoid the area during the day, when environmental light intensity rises.

It is still debated whether mesopelagic species possess a strong endogenous mechanism (i.e. biological clock) regulating their behavioural rhythms or whether they just respond to light cycles in an exogenous manner (Saigusa et al. 2000). The present study showed that Pasiphaea multidentata does not modify its verti- cal migratory behaviour in terms of phase of activity but rather changes the habitat in which it is performed. Juveniles are benthopelagic and adults are nektobenthic and individuals of both categories may be sensitive to different light intensity ranges depending on the environment where they move. In crayfish, this phenomenon is consistent with models describing a modification in circadian behaviour basing upon rearrangement in the coupling of a neural and a hormonal oscillator during ontogeny (Fuentes-Pardo et al. 2003). According to that mechanism, P. multidentata may have an endogenous control on its migratory behaviour, with sensitivity to light intensity levels increasing when maturity is reached.

In the Mediterranean Sea, light is present down to ca. 1000 m depth (Tobar \& Sardà 1992), with absorption and scattering progressively reducing and modifying its intensity and spectral quality with increasing depth (Herring 2003). All pasiphaeid shrimps undertake vertical movements over a wide depth range, including the superficial layers of the water column (Franqueville 1971). As a consequence, the setting of these vertical migratory rhythms upon light cycles (i.e. the zeitgeber, i.e. periodic stimulus) should be driven by a wavelength present over the entire depth range of the displacement. The only radiation fitting this requirement is that at $480-490 \mathrm{~nm}$, invariably present down to $500 \mathrm{~m}$ depth in the clearest ocean water (Jerlov 1968). Photopigments with a maximum in absorbance at this wavelength range should be found in photoreceptors of the majority of vertical-migrating mesopelagic decapods. Some benthic species, such as Nephrops norvegicus, in the same study area show a strong modulation of behaviour upon light intensity cycles (Aguzzi et al. 2003) based on visual pigments absorbing at $480 \mathrm{~nm}$ (Loew 1974). P. multidentata indeed shows maximum sensitivity to monochromatic light of this range (Frank \& Widder 1999).

Pasiphaeid shrimps may set their vertical movements following an optimum monochromatic light intensity interval of $480-490 \mathrm{~nm}$, the timing of which varies with depth depending on sun position and the resulting penetration angle of light at the sea surface. A relationship of this kind was reported by Tobar \& Sardà (1992) for captures of the red prawn Aristeus antennatus in deep areas of the middle and lower slope.

In the present study, a different quality of data patterns was reported for Pasiphaea multidentata during the autumn equinox and summer solstice. This is not due to a bias in the sampling method used (i.e. otter trawl gear of mesh size $27.5 \mathrm{~mm}$ ) since juveniles were sampled starting from $\mathrm{CL}=7-8 \mathrm{~mm}$ (data not shown). Seasonal variations in captures of $P$. multidentata were previously described on the upper slope of this region 
(e.g. Cartes 1998). From October to June captures diminish on the upper slope, while increasing on the middle slope (Cartes 1993a). This suggests a general decrease in the range of migratory displacement occurring in the population in summer, which may be coupled with the reproductive cycle. In autumnwinter, a maximum in mature females is recorded in the study area (Company et al. 2003). As a consequence, animals may augment their range of movement compared to spring-summer in order to retrieve more food to account for gonadal maturation. Conversely, spring-summer reproductive inactivity may lead to a decrease in the range of displacement by diverting resources to growth (Company et al. 2001).

In conclusion, the present work shows modulation of vertical migratory rhythm in Pasiphaea sivado and P. multidentata by light intensity cycles and seasonal variations in photoperiod length. The modification of this behaviour in adult $P$. multidentata does not refer to the phase of activity but rather refers to habitat choice in relation to predation pressure. Also, benthopelagic migration of juveniles, from upper slope to upper layers of the water column, takes place within larger bathymetric ranges than the nektobenthic movements of adults from upper to lower slope. Adults and juveniles therefore respond to light cycles of different intensity.

Acknowledgements. The authors thank Dr. F. Sardà, Chief Investigator of the project NERIT (MAR98-0935) funded by the Spanish CICYT and the crew of the RV 'García del Cid' (CSIC) for their support during sampling. Special thanks also to B. Molí and A. Castellón for their valuable help during sampling operations. J. Aguzzi is a Postdoctoral Fellow on the Juan de la Cierva Program.

\section{LITERATURE CITED}

Abelló P, Carbonell A, Torres P (2002) Biogeography of epibenthic crustaceans on the shelf and upper slope off the Iberian Peninsula Mediterranean coasts: implications for the establishment of natural management areas. Sci Mar 66(Suppl 2):183-198

Aguzzi J, Sardà F, Abelló P, Company JB, Rotllant G (2003) Diel and seasonal patterns of Nephrops norvegicus (Decapoda: Nephropidae) catchability in the western Mediterranean. Mar Ecol Prog Ser 258:201-211

Aguzzi J, Company JB, Abelló P (2006) Rhythmic behaviour of the burying prawn Solenocera membranacea (Decapoda: Penaeoidea: Solenoceridae) in the western Mediterranean: a perspective through depth and season. Bull Mar Sci 79:353-364

Bergstand AO, Wik ÅD, Hildre Ø (2003) Predator-prey relationship and sources of the Skagerrak deep-water fish assemblages. J Nat Fish Sci 31:165-180

Bertrand JA, Gil de Sola L, Papaconstantinou C, Relini G, Souplet A (2002) The general specifications of the MEDITS surveys. Sci Mar 66(Suppl 2):9-17

Cartes JE (1993a) Day-night feeding by decapod crustaceans in a deep-water bottom community in the western Mediterranean. J Mar Biol Assoc UK 73:795-811
Cartes JE (1993b) Feeding habits of pasiphaeids shrimps close to the bottom on the western Mediterranean slope. Mar Biol 117:459-468

Cartes JE (1998) Dynamics of the bathyal benthic boundary layer in the northwester Mediterranean: depth and temporal variations in macrofaunal-megafaunal communities and their possible connections within deep-sea trophic webs. Prog Oceanogr 41:111-139

Cartes JE, Sardà F, Company JB, Lleonart J (1993) Daynight migrations by deep-sea decapod crustaceans in experimental samplings in the Western Mediterranean sea. J Exp Mar Biol Ecol 171:63-73

Company JB, Cartes JE, Sardà F (2001) Biological patterns and near-bottom population characteristics of 2 pasiphaeid decapod crustacean species, Pasiphaea sivado and P. multidentata, in the north-western Mediterranean Sea. Mar Biol 139:61-73

Company JB, Sardà F, Puig P, Cartes JE, Palanques A (2003) Duration and timing of reproduction in decapod crustaceans of the NW Mediterranean continental margin: is there a general pattern? Mar Ecol Prog Ser 261:201-216

De Robertis A (2002) Size-dependent visual predation risk and the timing of vertical migration: an optimization model. Limnol Oceanogr 47:925-933

Dunlap JC, Loros JJ, DeCursey P (2004) Chronobiology: Biological timekeeping. Sinauer Associates, Sunderland, MA

Fanelli M, Cartes JE (2004) Feeding habits of pandalid shrimps in the Alboran Sea (SW Mediterranean): influence of biological and environmental factors. Mar Ecol Prog Ser 280:227-238

Frank T (2003) Effects of light adaptation on the temporal resolution of deep-sea crustaceans. Integr Comp Biol 43: 559-570

Frank TM, EA Widder (1999) Comparative study of the spectral sensitivities of mesopelagic crustaceans. J Comp Physiol 185:255-265

Franqueville C (1971) Macroplancton profond (Invertébrés) de la Méditerranée nord occidental. Téthys 3:11-56

Fuentes-Pardo B, Guzmán Gómez AM, Lara Aparicio M, López de Medrano S (2003) A qualitative model of a motor circadian rhythm. Bio Syst 71:61-69

Herring P (2003) The biology of the deep ocean. Biology of habitats. Oxford University Press, New York

Johnsen S (2005) The red and the black: bioluminescence and the colour of animals in the deep sea. Integr Comp Biol 45: $234-246$

Jerlov NG (1968) Optical oceanography. Elsevier, Amsterdam

Joshi A (2005) Behaviour genetic in the post-genomics era: From genes to behaviour and vice versa. Curr Sci 89: 1128-1135

Kronfeld-Schor N, Dayan T (2003) Partitioning of time as an ecological resource. Annu Rev Ecol Evol Syst 34:153-181

Lagardère JP (1977) Recherches sur le régime alimentaire et le comportement prédateur des décapodes benthiques de la pente continentale de l'Atlantique Nord Oriental (Golfe de Gascogne et Maroc). In: Keegan BF, Ceidigh PO, Boaden PJS (eds) Biology of benthic organisms. Oxford, Pergamon Press, p 397-408

Loew ER (1974) Light-induced rhabdometric degeneration in the Norway lobster, Nephrops norvegicus (L.). ICES CM/K: 29

Macquart-Moulin C, Patriti G (1996) Accumulation of migratory micronekton crustaceans over the upper slope and submarine canyons of the northwester Mediterranean. Deep-Sea Res I 43:579-602

McIntosh AR, Townsend CR (1994) Interpopulation variation in mayfly antipredator tactics: differential effects of con- 
trasting predatory fish. Ecology 75:2078-2090

Naylor E (2005) Chronobiology: implications for marine resources exploitation and management. Sci Mar 69 (Suppl 1):157-167

Naylor E, Kennedy F (2003) Ontogeny of behavioural adaptations in beach crustaceans: some temporal considerations for integrated coastal zone management and conservation. Estuar Coast Shelf Sci 58:169-175

Oishi K, Saigusa M (1997) Nighttime emergence patterns of planktonic and benthic crustaceans in a shallow subtidal environment. J Oceanogr 53:611-621

Saigusa M, Akiyama T (1995) The tidal rhythm of emergence, and the seasonal variation of this synchrony, in an intertidal midge. Biol Bull 188:166-178

Saigusa M, Oishi K, Ikumoto A, Iwasaki H, Terajima M (2000)

Editorial responsibility: Howard Browman (Associate Editorin-Chief), Storebø, Norway
Emergence patterns of small subtidal arthropods in relation to day/night, tidal and surface/bottom factors: Investigations in the Boreal Sea, Japan (Akkeshi, Hokkaido). J Oceanogr 56:295-310

Sardà F, Company JB, Castellón A (2003) Intraspecific aggregation structure of a shoal of Western Mediterranean (Catalan coast) deep-sea shrimp, Aristeus antennatus (Risso, 1816), during the reproductive period. J Shellfish Res 22:569-579

Sparre P, Ursin E, Vemena SC (1989) Introduction to tropical fish stock assessment Part 1. Manual FAO fisheries technical paper (306/1). FAO, Rome

Tobar R, Sardà F (1992) Annual and diel light intensity cycle as a predictive factor in deep-water fisheries for the prawn Aristaeus antennatus Risso, 1816. Fish Res 15:196-179

Submitted: May 4, 2006; Accepted: October 10, 2006 Proofs received from author(s): April 4, 2007 